\title{
"Predictive Factors of Malignancy in Pediatric Patients with Thyroid Nodules and Performance of the Italian Classification (SIAPEC 2014) in the Outcome of the Cytological FNA Categories"
}

\author{
Gerdi Tuli ( $\nabla$ gerdi.tuli@unito.it ) \\ Ospedale Infantile Regina Margherita https://orcid.org/0000-0001-5862-8958 \\ Jessica Munarin \\ Ospedale Infantile Regina Margherita \\ Erica Agosto \\ Ospedale Infantile Regina Margherita \\ Patrizia Matarazzo \\ Ospedale Infantile Regina Margherita \\ Francesco Quaglino \\ Maria Vittoria Hospital: Ospedale Maria Vittoria \\ Alberto Mormile \\ Azienda Ospedaliera Ordine Mauriziano di Torino \\ Luisa De Sanctis \\ Ospedale Infantile Regina Margherita
}

Research Article

Keywords: thyroid nodule, pediatric, FNAB, cytological category, outcome

Posted Date: May 12th, 2021

DOI: https://doi.org/10.21203/rs.3.rs-506450/v1

License: (c) (1) This work is licensed under a Creative Commons Attribution 4.0 International License. Read Full License 


\section{Abstract}

Purpose: The rate of malignancy (ROM) among pediatric studies using the Bethesda System is $39.5 \%$ and $41.5 \%$ for atypia of undetermined significance/follicular lesion of undetermined significance and for suspected follicular neoplasm, respectively. Data reported on the basis of Bethesda System system showed lower ROM in adults with indeterminate nodules (30.5\% and $28.9 \%$ respectively). Studies on adults based on the Italian Society of Anatomic Pathology and Cytology (SIAPEC) classification, report ROM of $14.2 \%$ for TIR3a and $44.6 \%$ for TIR3b category, showing greater sensitivity in detecting malignancy. To date, no performance data are available about SIAPEC classification in pediatric age.

Methods: retrospective data were collected from 200 pediatric subjects with thyroid nodules in the period 2000-2020.

Results: The distribution of cytological categories after fine needle aspiration biopsy (FNAB) was 7 TIR1, 4 TIR1c, 22 TIR2, 14 TIR3a, 9 TIR3b, 3 TIR4 and 16 TIR5. Surgical approach was performed in 40/200 subjects, with total ROM of 65\% (0\% for TIR1-TIR3a, $77.8 \%$ for TIR3b and $100 \%$ for TIR4-TIR5). Total FNAB accuracy was $95 \%$, while the sensibility and specificity were $92.3 \%$ and $92.6 \%$, respectively.

Conclusions: The reported data seem to confirm a greater sensitivity of SIAPEC classification to identify malignancy within the indeterminate category also in pediatric age and not only in adulthood. This finding may orient clinicians towards clinical follow-up for the indeterminate TIR3a group and towards surgical approach with total thyroidectomy in the indeterminate TIR3b group, although this indication should be confirmed in further national multicenter studies including larger cohorts.

\section{Introduction}

Nodular thyroid disease in pediatric age has a lower prevalence (0.2-5.1\%) than in adulthood (1-10\%) [1-3], but the main difference between pediatric and adult age lies in the rate of malignancy (ROM) (16-26\% vs 5-10\%) [4-5]. Differentiated thyroid cancer (DTC), which occurs mainly in adolescence and in females, accounts for $30 \%$ of endocrine tumors, which in turn represent $4-5 \%$ of all childhood neoplasms [6-7]. Among DTCs, papillary thyroid cancer (PTC) is the most frequent histological type (90\%), while follicular thyroid cancer (FTC) and medullary thyroid cancer (MTC) are rare [8-9]. Thyroid disease, radiation exposure, previous neoplasms, family history, young age, male gender, and genetic predisposition are considered to be the most important risk factors for developing thyroid cancer [1-20].

Anamnestic and clinical data, thyroid hormone profile, and ultrasound evaluation are critical for the initial assessment [10-21]. Ultrasound features suspected for malignancy include nodule size $>1 \mathrm{~cm}$, hypoechogenicity, intranodal vascularity or microcalcifications, irregular borders and neck lymph nodes [21-29]. Once suspicious ultrasound features are present, fine needle aspiration biopsy (FNAB) is required to determine the cytological category. The most widely used cytological classifications are the Bethesda System for Reporting Thyroid Cytopathology (BSRTC) and the British Thyroid Association (BTA) Guidance on the reporting thyroid cytology; in Italy, the Italian Society of Anatomic Pathology and Cytology (SIAPEC) in 2014 reviewed the cytological categories, indicating a five-tiered classification and subdividing the 'indeterminate for malignancy' class into the 'TIR3a' low risk indeterminate lesion (LRIL) and the 'TIR3b' high risk indeterminate lesion (HRIL) due to the follicular features of the neoplasia (Table 1) [30-32].

In adulthood, each category has a ROM that varies according to the classification system used; to date few data on pediatric age are available. All classification systems include categories for non-diagnostic cytology samples, benign lesions, and malignant lesions, but differ in the terminology of borderline lesions. The BSRTC indicates two distinct categories for borderline lesions: "Atypia of undetermined significance (AUS)/follicular lesion of undetermined significance (FLUS)" and "suspicious follicular neoplasm (SFN)" (III-IV categories). The British system uses the "ThyllI" category for all borderline cases, differentiating in "Thyllla" the possible neoplasm with atypia and in "ThyllIf" the possible follicular neoplasm, similar to the SIAPEC classification.

For the adult population, some Italian Authors have studied national cohorts affected by thyroid nodules and reported significantly higher sensitivity of the Italian system than the Bethesda one, validating the TIRa/TIR3b subclassification for the individuation of benign nodules and malignant tumors, with a rate of malignancy of $4-20.8 \%$ and $28-60.3 \%$, respectively [33-44]. Pediatric studies based on the BSRTC system indicate a higher ROM for indeterminate nodules (39.5\% for AUS/FLUS category and $41.5 \%$ for the SFN

Page 2/16 
category) compared to adults ( $30.5 \%$ and $28.9 \%$ respectively), with no substantial differences in ROM between the two indeterminate categories in both pediatric and adult age [46-59].

To our knowledge, according to the SIAPEC classification, no pediatric ROM data are currently available for each cytological category. The aim of this retrospective study is to represent the clinical features of pediatric patients with thyroid nodules and to analyze the ROM and the outcomes between the indeterminate cytological categories TIR3a and TIR3b.

\section{Materials And Methods}

This retrospective study included all subjects younger than 18 years-old with thyroid nodules greater than $0.5 \mathrm{~cm}$ referred to the Tertiary Center for Pediatric Endocrinology of Regina Margherita Children's Hospital in Turin in the period 2000-2020. After approval by the Institute's Ethical Committee, clinical, laboratory and radiographic data were collected from electronic medical records. Age, sex, familiarity and previous radiation exposure were documented. Patients were classified as euthyroid, hypothyroid or hyperthyroid based on serum levels of thyrotropin, free thyroxine and free triiodothyronine. Serum calcitonin was obtained in all patients with a history of medullary thyroid cancer or nodules larger than $1 \mathrm{~cm}$. All patients underwent thyroid ultrasound evaluation, which included the nodule diameter and the echoic pattern, classified as anechoic, hypoechoic, isoechoic, hyperechoic, or mixed. Lymph node changes, such as rounded bulging shape, irregular margins, increased size, absence of echogenic hilum, heterogeneous echoic pattern, presence of calcifications or cystic areas, and irregular vascularity were recorded. Technetium $\mathrm{Tc}^{99}$ scintiscan was performed only in hyperthyroid subjects. A cytological sample was obtained through ultrasound-guided fine needle aspiration biopsy (FNAB) in case of nodules greater than $1 \mathrm{~cm}$ or in case of suspicious features of malignancy at ultrasound evaluation. The cytological category was defined according to the SIAPEC classification. In its 2014 revision, the previous category of indeterminate cytology (TIR3) was further divided into TIR3A (low risk) and TIR3B (high risk due to features of follicular neoplasm). In subjects undergoing surgery for lobectomy or total thyroidectomy, histological specimens were also obtained. All specimens were evaluated by a single pathologist and have been reviewed for the study and the previous TIR3 category was reclassified in the new TIR3a and TIR3b categories by the same pathologist.

Statistical analysis and graphs construction were performed using Graphpad 7 (GraphPad Software, La Jolla, CA, USA). The sensitivity of FNAB (number of true positives divided by the sum of true positives and false negatives), its specificity (number of true negatives divided by the sum of true negatives and false positives), and diagnostic accuracy (sum of true positives and true negatives divided by the number of the sample) were calculated based on the results of patients undergoing both FNAB and surgery. Differences between groups were established by t test to compare mean values of continuous variables. For sample sizes smaller than 15, a Fisher exact test was used. The calculations were considered statistically significant when the P-value was less than 0.05 .

\section{Results}

We collected the clinical, laboratory and ultrasound retrospective data of 200 subjects ( 119 females and 81 males, 174 benign and 26 malignant nodules) younger than 18 years-old with thyroid nodules (Table 2). The overall rate of malignancy (ROM) observed was $13 \%$, which rises up to $26 \%$ if nodules with a diameter greater than $1 \mathrm{~cm}$ were considered. The mean age at diagnosis was 11.6 years-old (range 2-18), with a mean duration of follow-up of 8.6 years. Female to male ratio was 1.47, dropping to 1.27 by considering malignant nodules.

Familial anamnesis for autoimmune thyroid disease was positive in 108/200 (53.9\%), while 69/200 subjects (34.6\%) had autoimmune thyroid disease. Radiation exposure due to previously radiotherapy-treated cancer was present in $28 / 200$ (14.1\%) of subjects. No risk factors were found in $35 / 200$ (17.3\%) of cases. Regarding the risk factors investigated, no difference was observed among benign and malignant nodules.

Laboratory data showed mean TSH levels of $2.01 \mathrm{mcUl} / \mathrm{ml}$ (0.1-5.3), mean fT4 levels of $11.5 \mathrm{pg} / \mathrm{ml}$ (1.05-31.4), and mean fT3 levels of $4.09 \mathrm{pg} / \mathrm{ml}$ (2.3-4.6). TSH levels was significantly lower in subjects with a benign nodule than in subjects with a malignant nodule, being $1.94 \mathrm{mcUl} / \mathrm{ml}(0.1-4.9)$ vs $2.56 \mathrm{mcUl} / \mathrm{ml}(0.86-5.3)$, respectively $(\boldsymbol{p}=0.01)$. No differences were observed for fT4 and fT3 levels or for the presence of anti-peroxidase and anti-thyroglobulin antibodies. 
Ultrasound evaluation showed the localization of the nodule in the right lobe in 92 subjects (46\%), the involvement of the left lobe in 91 subjects $(45.5 \%)$ and the bilateral localization in 17 (8.5\%). Bilateral and right lobe involvement was associated with a higher malignancy rate than left lobe localization ( $23.6 \%$ vs $18.5 \%$ vs $5.5 \%$ malignancy rate, respectively, $\boldsymbol{p}=0.01)$. Intranodal vascularization was present in 61/200 (30.4\%), while intranodal calcification in 23/200 (11.5\%); both were associated with higher malignancy rate $(\boldsymbol{p}=0.003$ and $\boldsymbol{p}=\mathbf{0 . 0 0 9}$, respectively $)$, as well as lymph node involvement $(\boldsymbol{p}<0.0001)$ A larger nodule diameter was significantly more present in the malignant nodule than in the benign nodule group (mean diameter $24 \mathrm{~mm}$ vs $8 \mathrm{~mm}$, respectively, $p=<0.001$ ). The hypoechoic pattern was the most frequently observed ultrasound feature for both groups, with no correlation with the rate of malignancy.

When considering the indeterminate cytology category, no differences were observed in terms of age, gender, family history, genetic mutations, radiation exposure, thyroid hormone profile and ultrasound pattern, as well as the presence of intranodal calcifications or vascularization (Table 3). Localization of the nodule in the right lobe and larger diameter were associated with a higher rate of malignancy ( $\boldsymbol{p}=0.01$ and $\boldsymbol{p}<0.003$ respectively), as well as lymph node involvement $(\boldsymbol{p}<0.0001)$.

Of the 174 subjects with benign nodules, 125 were evaluated by periodical clinical and ultrasound check, FNAB was performed in 49 subjects, whereas 14 underwent to surgery.

FNAB was performed on the basis of nodule size and ultrasound feature in 75/200 (37.5\%) of subjects, including 7 TIR1 (9.3\%), 4 TIR1c (5.3\%), 22 TIR2 (29.3\%), 14 TIR3a (18.7\%), 9 TIR3b (12\%), 3 TIR4 (4\%) and 16 TIR5 (21.4\%) (Table 4).

Surgery was performed in $40 / 200(20 \%)$, with a total malignancy rate of $65 \%$ ( $0 \%$ for the TIR1-TIR3a, $77.8 \%$ for the TIR3b and $100 \%$ for the TIR4-TIR5 categories).

Of the 14 subjects with cytological category TIR3a, 6 underwent surgery, 5 by lobectomy, with a histological diagnosis of thyroid adenoma, and 1 by total thyroidectomy, with histological diagnosis of multinodular struma. The mean duration of follow-up was 4.6 years and FNAB was repeated in the remaining 8 subjects every 12-18 months, with confirmation of the cytological category.

All subjects with indeterminate TIR3b category underwent surgery; 7 of them underwent total thyroidectomy, with final diagnosis of papillary DTC in 5 cases, follicular DTC in 1 case and papillary microcarcinoma in 1 case, while the remaining 2 subjects underwent lobectomy, with final diagnosis of multinodular struma.

All subjects with cytological categories TIR4-TIR5 underwent total thyroidectomy and histological analysis confirmed a papillary DTC in all cases.

The total accuracy of FNAB was 95\%. For the benign low-risk categories TIR1-TIR2 and the malignant categories TIR4-TIR5 the FNAB showed $100 \%$ accuracy, whereas for indeterminate categories TIR3a and TIR3b accuracy was $100 \%$ and $77.8 \%$ respectively. The sensitivity and specificity of FNAB for all categories was $92.3 \%$ and $92.6 \%$, respectively.

\section{Discussion}

Nodular thyroid disease in pediatric age is a rare condition with prevalence of $0.2-5.1 \%$, much lower that of the adult population (1$10 \%$; however, children and adolescents are known to have a higher malignancy rate (12.5-50\%), with an average rate of $20-25 \%$, much higher than the adult population of $5-10 \%$ [1-7]. The malignancy rate in our cohort was $13 \%$, by considering the whole group, and $26 \%$ by considering the subjects with nodules greater than $1 \mathrm{~cm}$, similar to previous data of the literature. The observed female to male ratio was 1.47 , decreasing to 1.27 when malignant nodules are considered. Gender, previous thyroid disease and radiation exposure were not related to malignancy. As previously shown by several Authors, TSH levels were directly related to malignancy [20, 46-49]. Larger nodule size, presence of intranodal calcification or vascularity and lymph node involvement were also associated with malignancy, as previously reported [1-3, 22-25]. Other Authors have also indicated that hypoechogenicity and suspected neck lymph nodes are related to malignant neoplasms [21-29]. In our cohort, no difference in the echoic pattern was observed, but the bilateral localization of the nodule and its presence in the right lobe were significantly associated with a higher rate of malignancy, a finding to our knowledge so far not yet reported before in the literature. 
Nodules larger than $1 \mathrm{~cm}$ or with ultrasound features suspected of malignancy are subjected to echo-guided fine needle aspirate biopsy (FNAB). The 2014 Consensus Statement of the Italian Society of Anatomic Pathology and Cytology (SIAPEC) revised the cytological classification by diving the previous indeteminate category TIR3 in two sub-categories: TIR3a, if the lesion is considered low risk, and TIR3b, if considered at high risk. Clinical follow-up and eventual repetiton of FNAB is the recommended approach for TIR3a nodules, while surgery for TIR3b nodules. It is noteworthy that, before 2014 , all TIR3 classified nodules were treated by surgical exeresis; the new classification therefore allows to avoid the excessive surgical approach in the nodules classified TIR3a. The BSRTC and BTA Guidance on the reporting thyroid cytology, which are the most worldwide used cytological classifications, also consider two categories of indeterminate lesion: atypia of undetermined significance or AUS/follicular lesion of undetermined significance or FLUS and "suspicious follicular neoplasm or SFN" (III-IV categories), the former; Thyllla, for possible neoplasm with atypia, and Thylllf, for possible neoplasm suggesting follicular neoplasm, respectively, the second. The main difference of the three cytologic classifications is in the indeterminate group. The interpretation of "atypia" features is different for the SIAPEC classification, which includes such nodules in TIRb category, while BTA and BSRTC include some of them in the THY3a and category III, respectively.

To our knowledge this is the first study that analyzes the performance of the SIAPEC cytology classification in pediatric age. We compared the data of our study with the results of similar studies on Italian adult cohorts and the main studies on pediatric cohorts based on the BSRTC classification (Table 5) [33-44, 46-60]. Italian studies based on the 2014 SIAPEC classification report an average malignancy rate of $14.2 \%$ for TIR3a nodules and $44.7 \%$ for the TIR3b cytological category in studies with adult cohorts [3344]. In our cohort we did not observe any malignancy among TIR3a nodules but the amount of histological data was very small, although the follow-up of 4.6 years confirmed the cytological category in all subjects who performed clinical follow-up with FNAB repeated every 12-18 months. The malignancy rate among subjects with TIR3b nodule was $77.8 \%$, which is much higher than the rate observed in adults, similarly to other studies reporting pediatric cohorts [54]. The mean observed malignancy rate among pediatric studies using the BSRTC system is $39.5 \%$ for AUS/FLUS category and $41.5 \%$ for the SFN category, demonstrating greater sensitivity of the SIAPEC classification to sort out benign nodules and malignancies also in pediatric age. A recent meta-analysis based on the BSRTC system showed a lower rate of malignancy in adults with indeterminate nodules (30.5\% and $28.9 \%$ respectively) with no substantial differences between the two categories AUS/FLUS and SFN as reported in pediatric studies [60]; this finding is especially important when deciding on the surgical approach.

ATA thyroid cancer guidelines for the pediatric age recommend surgery (lobectomy + isthmusectomy) for indeterminate FNAB categories in accordance with Bethesda classification. Considering that the 2014 SIAPEC classification seems to have a higher sensitivity to sort out benign and malignant nodules, the high rate of malignancy observed in the TIR3b group may orient towards clinical follow-up in the indeterminate TIR3a and total thyroidectomy in the TIR3b subcategory, especially in case of bilateral or of right lobe localization. However, further evidence is needed from studies with larger cohort sizes to confirm the significant gap in the ROM between TIR3a and TIR3b in pediatric age.

The present study was conducted in a single tertiary pediatric endocrinology center over a period of 20 years. The strengths are the experience acquired by the center and the centralization of the cytological and histological data. These data were also compared with the main pediatric studies based on the BSRTC system and with the main Italian studies on adults based on the SIAPEC classification. Given the apparent greater sensitivity of this classification, the reported data should encourage Italian endocrinologists to differentiate benign and malignant nodules within the indeterminate category, to better orient clinicians towards clinical follow-up or surgery follow-up management.

The study also has many limitations. The data are retrospective and the follow-up period after 2014 is too short. The size of the cohort with indeterminate nodules is too small to have a strong statistical relevance of the data presented, but the rarity of thyroid nodule in pediatric age should be considered, as well as the fact that the new SIAPEC classification was available starting from 2014.

In conclusion, this is the first pediatric study that analyzes the performance of the SIAPEC cytological classification for thyroid nodules. The data reported seem to confirm the greater sensitivity of this classification in identifying benign and malignant nodules in the indeterminate category also in pediatric age and not only in adults. This finding, together with the fact that a higher rate of malignancy was observed in pediatric age, may orient clinicians towards a surgical approach using total thyroidectomy in the 
indeterminate TIR3b group, although this hypothesis should be confirmed in further national multicenter studies with a larger cohort size.

\section{Declarations Funding:}

No grants or fellowship have supported this paper

\section{Conflict of Interest:}

All Authors declare that they have no conflict of interest.

\section{Availability of data and material:}

all data can be available upon request to the Corresponding Author

\section{Authors' Contribution:}

Gerdi Tuli, Patrizia Matarazzo and Luisa De Sanctis contributed to the study design, the statistical analysis and the revision of the first manuscript draft. Jessica Munarin and Erica Agosto contributed to the data collection, to the first draft of the manuscript and to the reference check. Francesco Quaglino and Alberto Mormile contributed to the study design and the revision of the first manuscript draft.

\section{Ethical approval:}

All procedures performed in studies involving human participants were in accordance with the ethical standards of the institutional and/or national research committee and with the 1964 Helsinki declaration and its later amendments or comparable ethical standards.

\section{Informed consent:}

Informed consent was obtained from all parents of the individual participants included in the study.

\section{Acknowledgements:}

N/A

\section{References}

1. Bauer AJ. Thyroid nodules in children and adolescents. Curr. Opin. Endocrinol. Diabetes. Obes. 26 266-274 (2019)

2. Bauer AJ. Pediatric thyroid cancer: genetics, therapy and outcome. Endocrinol. Metab. Clin. North. Am. 49, 589-611 (2020)

3. Niedziela M. Pathogenesis, diagnosis and management of thyroid nodules in children. Endocr. Relat. Cancer. 13, 427-453 (2006)

4. Corrias A, Mussa A, Baronio F, Arrigo T, Salerno M, Segni M, Vigone MC, Gastaldi R, Zirilli G, Tuli G, Beccaria L, lughetti L, Einaudi S, Weber G, De Luca F, Cassio A; Study Group for Thyroid Diseases of Italian Society for Pediatric Endocrinology and 
Diabetology (SIEDP/ISPED). Diagnostic Features of Thyroid Nodules in Pediatrics. Arch. Pediatr. Adolesc. Med. 164, 714-719 (2010)

5. Niedziela M. Thyroid nodules. Best. Pract. Res. Clin. Endocrinol. Metab. 28, 245-277 (2014)

6. Hogan AR, Zhuge Y, Perez EA, Koniaris LG, Lew JI, Sola JE. Pediatric Thyroid Carcinoma: Incidence and Outcomes in 1753 Patients. J. Surg. Res. 156, 167-172 (2009)

7. Parisi MT, Mankoff D. Differentiated Pediatric Thyroid Cancer: Correlates With Adult Disease, Controversies in Treatment. Semin. Nucl. Med. 37, 340-356 (2007)

8. Pritchard-Jones K, Kaatschb P, Steliarova-Foucher E, Stiller CA, Coebergh JW. Cancer in children and adolescents in Europe: Developments over 20 years and future challenges. Eur. J. Cancer. 42, 2183-2190 (2006)

9. Wells Jr A, Asa SL, Dralle H, Elisei R, Evans DB, Gagel RF, Lee N, Machens A, Moley JF, Pacini F, Raue F, Frank-Raue K, Robinson B, Rosenthal MS, Santoro M, Schlumberger M, Shah M, Waguespack SG; American Thyroid Association Guidelines Task Force on Medullary Thyroid Carcinoma . Revised American Thyroid Association Guidelines for the Management of Medullary Thyroid Carcinoma. Thyroid. 25, 567-610 (2015)

10. Corrias A, Cassio A, Weber G, Mussa A, Wasniewska M, Rapa A, Gastaldi R, Einaudi S, Baronio F, Vigone MC, Messina MF, Bal M, Bona G, de Sanctis C; Study Group for Thyroid Diseases of Italian Society for Pediatric Endocrinology and Diabetology (SIEDP/ISPED). Thyroid nodules and cancer in children and adolescents affected by autoimmune thyroiditis. Arch. Pediatr. Adolesc. Med. 162, 526-531 (2008)

11. Radetti G, Loche S, D’Antonio V, Salerno M, Guzzetti C, Aversa T, Cassio A, Cappa M, Gastaldi R, Deluca F, Vigone MC, Tronconi GM, Corrias A. Influence of Hashimoto Thyroiditis on the Development of Thyroid Nodules and Cancer in Children and Adolescents. J. Endocr. Soc. 3, 607-616 (2019)

12. Alvarez AL, Mulder M, Handelsman RS, Lew JI, Farra JC. High Rates of Underlying Thyroid Cancer in Patients Undergoing Thyroidectomy for Hyperthyroidism. J. Surg. Res. 245, 523-528 (2020)

13. Waguespack SG. Thyroid Sequelae of Pediatric Cancer. Horm. Res. Paediatr. 91, 104-117 (2019)

14. Sigurdson AJ, Ronckers SM, Mertens AC, Stovall M, Smith SA, Liu Y, Berkow RL, Hammond S, Neglia JP, Meadows AT, Sklar CA, Robison LL, Inskip PD . Primary thyroid cancer after a first tumour in childhood (the Childhood Cancer Survivor Study): a nested case-control study. The Lancet. 365, 2014-2023 (2005)

15. Pekova B, Dvorakova S, Sykorova V, Vacinova G, Vaclavikova E, Moravcova J, Katra R, Vlcek P, Sykorova P, Kodetova D, Vcelak J, Bendlova B. Somatic genetic alterations in a large cohort of pediatric thyroid nodules. Endocr. Connect. 8, 796-805 (2019)

16. Mostoufi-Moab S, Labourier E, Sullivan L, LiVolsi V, Li Y, Xiao R, Beaudenon-Huibregtse S, Kazahaya K, Adzick NS, Baloch Z, Bauer AJ . Molecular testing for oncogenic gene alterations in pediatric thyroid lesions. Thyroid. 28, 60-67 (2018)

17. Zdravkovic V. Update on the management of pediatric thyroid cancer. Adv. Pediatrics. Adol. Med. 1, 1-5 (2018)

18. Wells Jr SA, Santoro M. Targeting the RET Pathway in Thyroid Cancer. Clin. Cancer. Res. 2009 15, 7119-7123 (2009)

19. Waguespack SG, Rich TA, Perrier ND, Jimenez C, Cote GJ. Management of medullary thyroid carcinoma and MEN2 syndromes in childhood. Nat. Rev. Endocrinol. 7, 596-607 (2011)

20. Corrias A, Mussa A. Thyroid Nodules in Pediatrics: Which Ones Can Be Left Alone, Which Ones Must be Investigated, When and How. J. Clin. Res. Pediatr. Endocrinol. 5, 57-69 (2013)

21. Francis GL, Waguespack SG, Bauer AJ, Angelos P, Benvenga S, Cerutti JM, Dinauer CA, Hamilton J, Hay ID, Luster M., Parisi MT, Rachmiel M, Thompson GB, Yamashita S; American Thyroid Association Guidelines Task Force. Management Guidelines for Children with Thyroid Nodules and Differentiated Thyroid Cancer, The American Thyroid Association Guidelines Task Force on Pediatric Thyroid Cancer. Thyroid. 25, 716-759 (2015)

22. Moon WJ, Jung S, Lee JH, Na DG, Baek JH, Lee YH, Kim J, Kim HS, Byun JS, Lee DH; Thyroid Study Group, Korean Society of Neuro- and Head and Neck Radiology. Benign and Malignant Thyroid Nodules: US Differentiation-Multicenter Retrospective Study. Radiology. 247, 762-770 (2008)

23. Saavedra J, Deladoëy J, Saint-Vil D, Boivin Y, Alos N, Deal C, Van Vliet G, Huot C. Is Ultrasonography Useful in Predicting Thyroid Cancer in Children with Thyroid Nodules and Apparently Benign Cytopathologic Features? Horm. Res. Paediatr. 75, 269-275 (2011) 
24. Roy R, Kouniavsky G, Schneider E, Allendorf JD, Chabot JA, Logerfo P, Dackiw AP, Colombani P, Zeiger MA, Lee JA. Predictive factors of malignancy in pediatric thyroid nodules. Surgery. 150, 1228-1233 (2011)

25. Mussa A, De Andrea M, Motta M, Mormile A, Palestini N, Corrias A. Predictors of Malignancy in Children with Thyroid Nodules. J. Pediatr. 167, 886-892 (2015)

26. Singh Ospina N, Sebo TJ, Morris JC, Castro MR. The Value of Repeat Thyroid Fine-Needle Aspiration Biopsy in Patients with a Previously Benign Result: How Often Does It Alter Management? Thyroid. 25, 1121-1126 (2015)

27. Hess J, Schafernak K, Newbern D, Vern-Gross T, Foote J, Van Tassel D, Jamshidi R, Walsh A. Ultrasound is superior to palpation for thyroid cancer detection in high-risk childhood cancer and BMT survivors. Support. Care. Cancer. 28, 5117-5124 (2020)

28. Niedziela M. Thyroid nodules. Best. Pract. Res. Clin. Endocrinol. Metab. 28, 245-277 (2014)

29. A Corrias A, S Einaudi S, Chiorboli E, Weber G, Crinò A, Andreo M, Cesaretti G, de Sanctis L, Messina MF, Segni M, Cicchetti M, Vigone M, Pasquino AM, Spera S, de Luca F, Mussa GC, Bona G. Accuracy of Fine Needle Aspiration Biopsy of Thyroid Nodules in Detecting Malignancy in Childhood: Comparison with Conventional Clinical, Laboratory, and Imaging Approaches. J. Clin. Endocrinol. Metab. 86, 4644-4648 (2001)

30. Nardi F, Basolo F, Crescenzi A, Fadda G, Frasoldati A, Orlandi F, Palombini L, Papini E, Zini M, Pontecorvi A, Vitti P. Italian consensus for the classification and reporting of thyroid cytology. J. Endocrinol. Invest. 37, 593-599 (2014)

31. Cibas ES, Ali SZ. The 2017 Bethesda System for Reporting Thyroid Cytopathology. Thyroid. 27, 1341-1346 (2017)

32. Cross C, Chandra A, Giles T, Johnson S, Kocjan G, Poller D, Stephenson T. Guidance on the reporting of thyroid cytology specimens. January 2016. Available at: http://ukeps.com/docs/thyroidfna.pdf

33. Tartaglia F, Giuliani A, Tromba L, Carbotta S, Karpathiotakis M, Tortorelli G, Pelle F, Merola R, Donello C, Carbotta G, De Anna L, Conzo G, Sorrenti S, Ulisse S. Fine needle aspiration cytology of 650 thyroid nodules operated for multinodular goiter: a cytohistological correlation based on the new Italian cytological classification (siapec 2014). J. Biol. Regul. Homeost. Agents. 30 , 1187-1193 (2016)

34. Medas F, Erdas E, Gordini L, Conzo G, Gambardella C, Canu GL, Pisano G, Nicolosi A, Calò PG. Risk of malignancy in thyroid nodules classified as TIR-3A: What therapy? Int. J. Surg. 41, S60-S64 (2017)

35. Ulisse S, Bosco D, Nardi F, Nesca A, D'Armiento E, Guglielmino V, De Vito C, Sorrenti S, Pironi D, Tartaglia F, Arcieri S, Catania A, Monti M, Filippini A, Ascoli V. Thyroid Imaging Reporting and Data System Score Combined with the New Italian Classification for Thyroid Cytology Improves the Clinical Management of Indeterminate Nodules. Int. J. Endocrinol. 9692304. (2017) doi: $10.1155 / 2017 / 9692304$

36. Straccia P, Santoro A, Rossi ED, Brunelli C, Mosseri C, Musarra T, Pontecorvi A, Lombardi CP, Fadda G. Incidence, malignancy rates of diagnoses and cyto-histological correlations in the new Italian Reporting System for Thyroid Cytology: An institutional experience. Cytopathology. 28, 503-508 (2017)

37. Trimboli P, Fulciniti F, Merlo E, Barizzi J, Mazzucchelli L, Giovanella L. Histologic Outcome of Indeterminate Thyroid Nodules Classified at Low or High Risk. Endocr. Pathol. 29, 75-79 (2018)

38. Rullo E, Minelli G, Bosco D, Nardi F, Ascoli V. Evaluation of the Italian cytological subclassification of thyroid indeterminate nodules into TIR-3A and TIR-3B: a retrospective study of 290 cases with histological correlation from a single institution. J. Endocrinol. Invest. 41, 531-538 (2018)

39. Valabrega S, Santolamazza G, Romanelli F, Scapicchio G, D'Angelo F, Bellotti C, Aurello P, Izzo L, Giovagnoli MR, Trimboli P. Cancer Rate of the Indeterminate Lesions at Low or High Risk According to Italian System for Reporting of Thyroid FNA. Front. Endocrinol. (Lausanne). 10, 371 (2018) doi: 10.3389/fendo.2018.00371

40. Trimboli P, Guidobaldi L, Amendola S, Nasrollah N, Romanelli F, Attanasio D, Ramacciato G, Saggiorato E, Valabrega S, Crescenzi A. Galectin-3 and HBME-1 improve the accuracy of core biopsy in indeterminate thyroid nodules. Endocrine. 52, 39-45 (2016)

41. Quaglino F, Arnulfo G, Sandrucci S, Rossi C, Marchese V, Saracco R, Guzzetti S, Taraglio S, Mazza E. A Monocentric Retrospective Study about the Correlation between Histology and Cytology of Thyroid Indeterminate Nodules Classified as TIR 3A and TIR 3B, according to 2014 Italian Consensus for Classification and Reporting of Thyroid Cytology. Adv. Med. 3932721.37. (2019) doi: 10.1155/2019/3932721 
42. Rullo E, Minelli G, Bosco D, Nardi F, Grani G, Durante C, Ascoli V. Indeterminate thyroid nodules (TIR3A/TIR3B) according to the new Italian reporting system for thyroid cytology: A cytomorphological study. Cytopathology. 30, 475-484 (2019)

43. Sparano C, Parenti G, Cilotti A, Bencini L, Calistri M, Mannucci E, Biagini C, Vezzosi V, Mannelli M, Forti G, Petrone L. Clinical impact of the new SIAPEC-IAP classification on the indeterminate category of thyroid nodules. J. Endocrinol. Invest. 42, 1-6 (2019)

44. Cozzolino A, Pozza C, Pofi R, Sbardella E, Faggiano A, Isidori AM, Giannetta E, Pernazza A, Rullo E, Ascoli V. Lenzi A, Gianfrilli D. Predictors of malignancy in high-risk indeterminate (TIR3B) cytopathology thyroid nodules. J Endocrinol. Invest. 43, 1115-1123 (2020)

45. Trimboli P, Crescenzi A, Castellana M, Giorgino F, Giovanella L, Bongiovanni M. Italian consensus for the classification and reporting of thyroid cytology: the risk of malignancy between indeterminate lesions at low or high risk. A systematic review and meta-analysis. Endocrine. 63, 430-438 (2019)

46. Monaco SE, Pantanowitz L, Khalbuss WE, Benkovich VA, Ozolek J, Nikiforova MN, Simons JP, Nikiforov YE. Cytomorphological and molecular genetic findings in pediatric thyroid fine-needle aspiration. Cancer. Cytopathol. 120, 342-350 (2012)

47. Rossi ED, Straccia P, Martini M, Revelli L, Lombardi CP, Pontecorvi A, Fadda G. The role of thyroid fine- needle aspiration cytology in the pediatric population: an institutional experience. Cancer. Cytopathol. 122, 359-367 (2014)

48. Lale SA, Morgenstern NN, Chiara S, Wasserman P. Fine needle aspiration of thyroid nodules in the pediatric population: a 12year cyto-histological correlation experience at North Shore-Long Island Jewish Health System. Diagn. Cytopathol. 43, 598 604 (2015)

49. Norlen O, Charlton A, Sarkis LM, Henwood T, Shun A, Gill AJ, Delbridge L. Risk of malignancy for each Bethesda class in pediatric thyroid nodules. J. Pediatr. Surg. 50, 1147 - 1149 (2015)

50. Buryk MA, Simons JP, Picarsic J, Monaco SE, Ozolek JA, Joyce J, Gurtunca N, Nikiforov YE, Feldman Witchel S. Can malignant thyroid nodules be distinguished from benign thyroid nodules in children and adolescents by clinical characteristics? A review of 89 pediatric patients with thyroid nodules. Thyroid. 25, 392- 400 (2015)

51. Amirazodi E, Propst EJ, Chung CT, Parra DA, Wasserman JD. Pediatric thyroid FNA biopsy: outcomes and impact on management over 24 years at a tertiary care center. Cancer. Cytopathol. 124, 801-810 (2016)

52. Pantola C, Kala S, Khan L, Pantola S, Singh M, Verma S. Cytological diagnosis of pediatric thyroid nodule in perspective of the Bethesda Sy stem for Reporting Thyroid Cytopathology. J. Cytol. 33, 220-223 (2016)

53. Partyka KL, Huang EC, Cramer HM, Chen S, Wu HH. Histologic and clinical follow-up of thyroid fine-needle aspirates in pediatric patients. Cancer. Cytopathol. 124, 467-471 (2016)

54. CE Cherella, TE Angell, DM Richman, Frates MC, Benson CB, Moore FD, Barletta JA, Hollowell M, Smith JR, Alexander EK, Cibas ES, Wassner AJ. Differences in Thyroid Nodule Cytology and Malignancy Risk Between Children and Adults. Thyroid. 29, 10971104 (2019)

55. Heider A, Arnold S, Lew M, Pang J, Rabah R, Bruch S, Thomas I, Menon R, Cantley R, Davenport R, Jing X. Malignant risk of indeterminate pediatric thyroid nodules - an institutional experience. Diagn. Cytopathol. 47, 993-998 (2019)

56. Kardelen Al AD, Yılmaz C, Poyrazoglu S, Tunca F, Bayramoglu Z, Bas F, Bundak R, Gilse Senyurek Y, Ozluk Y, Yegen G, Yeşil S, Darendeliler $\mathrm{F}$. The role of thyroid fine-needle aspiration cytology in the treatment and follow-up of thyroid nodules in the pediatric population. Acta. Endocrinol. (Buchar). 15, 333-341 (2019)

57. Wang HY, Mehrad M, Ely KA, Liang J, Solórzano CC, Neblett WW 3rd, Coogan AC, Weiss VL. Incidence and malignancy rates of indeterminate pediatric thyroid nodules. Cancer. Cytopathol. 127, 231-239 (2019)

58. Suh J, Choi HS, Kwon A, Liang J, Solórzano CC, Neblett WW 3rd, Coogan AC, Weiss VL. Adolescents with thyroid nodules: retrospective analysis of factors predicting malignancy. Eur. J. Pediatr. 179, 317-325 (2020)

59. Vuong HG, Suzuki A, Na HY, Tuyen PV, Khuy DM, Nguyen HC, Jitpasutham T, Abelardo A, Amano T, Park SY, Jung CK, Hirokawa M, Katoh R, Kakudo K, Bychkov A. Application of the Bethesda System for Reporting Thyroid Cytopathology in the Pediatric Population. Am. J. Clin. Pathol. 155, 680-689 (2021)

60. Vuong HGG, Chung DGB, Ngo LM, Bui TQ, Hassell L, Jung CK, Kakudo K, Bychkov A. The use of the Bethesda system for reporting thyroid cytopathology in pediatric thyroid nodules - A meta-analysis. Thyroid. (2021) doi: 10.1089/thy.2020.0702. 
Tables

Table 1

SIAPEC, Bethesda and BTA cytological categories, rate of malignancy for each category and suggested management approach.

\begin{tabular}{|c|c|c|c|c|c|c|c|c|}
\hline SIAPEC & & & BSRTC & & & BTA & & \\
\hline Category & ROM & $\begin{array}{l}\text { Suggested } \\
\text { approach }\end{array}$ & Category & ROM & $\begin{array}{l}\text { Suggested } \\
\text { approach }\end{array}$ & Category & ROM & $\begin{array}{l}\text { Suggested } \\
\text { approach }\end{array}$ \\
\hline TIR1/TIR1C & \multirow[t]{2}{*}{$\begin{array}{l}\text { Not } \\
\text { defined }\end{array}$} & \multirow[t]{2}{*}{$\begin{array}{l}\text { Repeat } \\
\text { FNAB }\end{array}$} & & \multirow[t]{2}{*}{$\begin{array}{l}5- \\
10 \%\end{array}$} & \multirow[t]{2}{*}{$\begin{array}{l}\text { Repeat } \\
\text { FNAB }\end{array}$} & THY1/THY1C & \multirow[t]{2}{*}{$4 \%$} & \multirow[t]{2}{*}{$\begin{array}{l}\text { Repeat } \\
\text { FNAB }\end{array}$} \\
\hline ND/Cystic & & & ND & & & ND/Cystic & & \\
\hline
\end{tabular}

Undiagnostic or cystic

but not colloidal

$\begin{array}{lllllllll}\text { TIR2 } & <3 \% & \text { Follow-up } & \text { II } & 0-3 \% & \text { Follow-up } & \text { THY2/THY2c } & 1.4 \% & \text { Follow-up } \\ \text { NM / B } & & & \text { B } & & & \text { B } & & \end{array}$

Colloidal or hyperplastic

cystic lesions

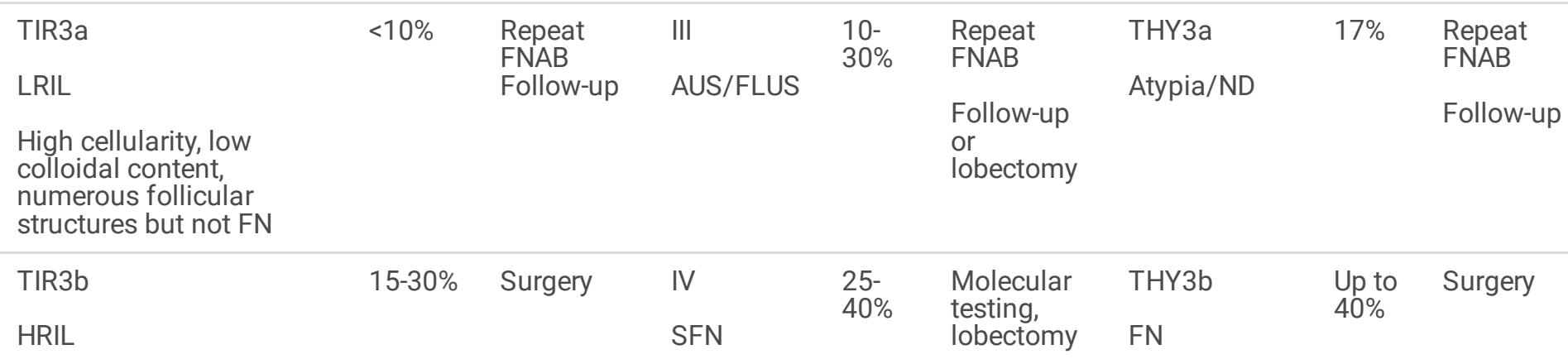

High cellularity,

monotone disposition in

microfollicular/trabecular

structures and

low/absent colloidal

content: FN

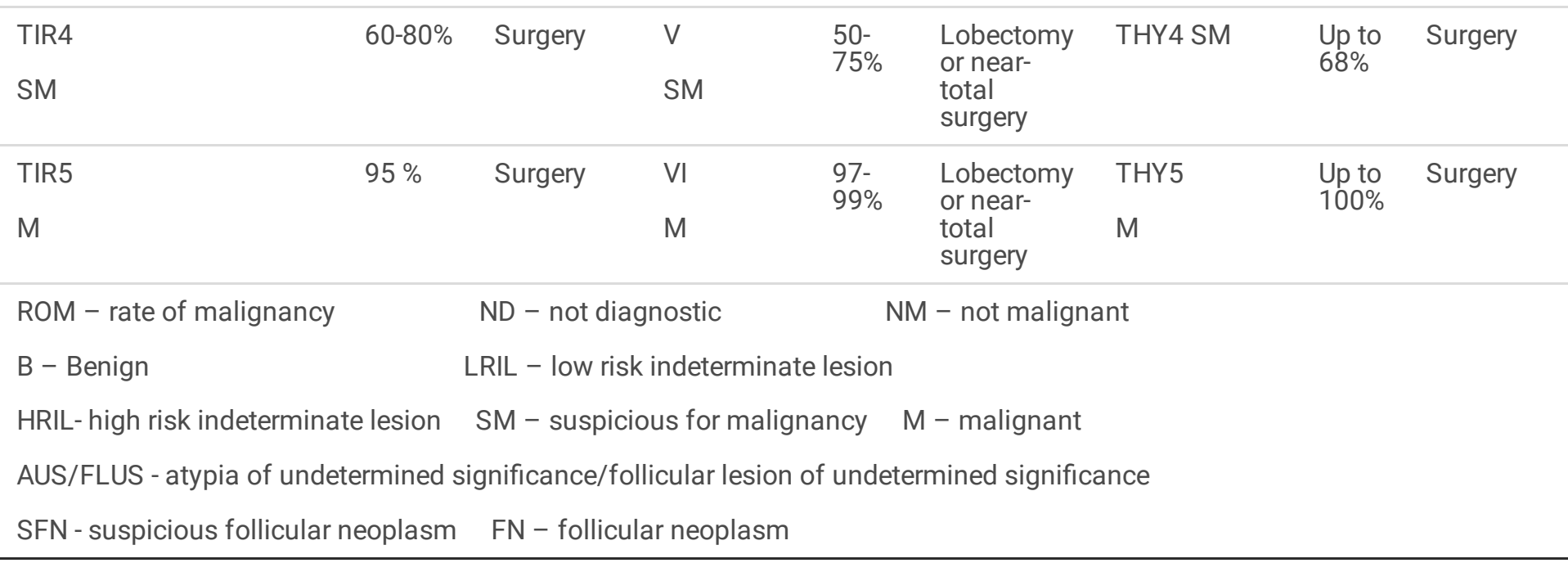


Table 2

Clinical, biochemical and US features of all subjects $(\mathrm{N}=200)$ with thyroid nodule

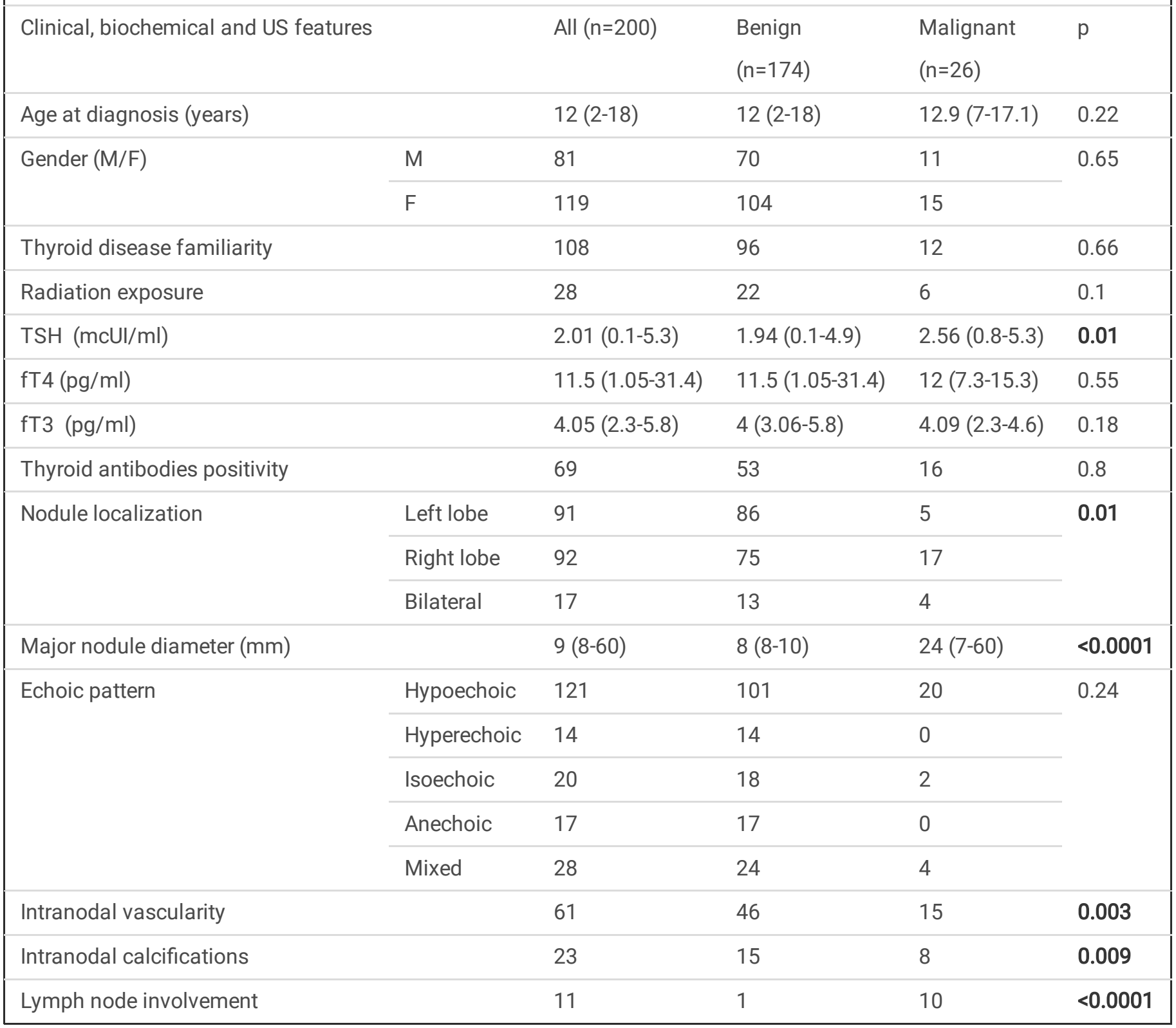


Table 3

\begin{tabular}{|c|c|c|c|c|}
\hline \multicolumn{2}{|l|}{ Clinical, biochemical and US features } & $\begin{array}{l}\text { TIR3a } \\
(n=14)\end{array}$ & $\begin{array}{l}\text { TIR3b } \\
(n=9)\end{array}$ & $\mathrm{p}$ \\
\hline Age at diagnosis (years) & & $13.25(6-17.5)$ & $13(6-15)$ & 0.66 \\
\hline \multirow[t]{2}{*}{ Gender (M/F) } & M & 7 & 5 & \multirow[t]{2}{*}{0.62} \\
\hline & $\mathrm{F}$ & 7 & 4 & \\
\hline Thyroid disease familiarity & & 0 & 2 & 0.99 \\
\hline Radiation exposure & & 3 & 1 & 0.22 \\
\hline TSH (mcUl/ml) & & $1.95(0.22-4.9)$ & $1.6(1.09-3.34)$ & 0.6 \\
\hline $\mathrm{fT} 4(\mathrm{pg} / \mathrm{ml})$ & & $12.1(9.1-13.8)$ & $12.7(10.5-14.9)$ & 0.2 \\
\hline fT3 (pg/ml) & & $4.2(3.2-5.8)$ & $4.3(2.3-4.6)$ & 0.18 \\
\hline Thyroid antibodies positivity & & 0 & 2 & 0.15 \\
\hline \multirow[t]{3}{*}{ Nodule localization } & Left lobe & 12 & 2 & \multirow[t]{3}{*}{0.01} \\
\hline & Right lobe & 2 & 6 & \\
\hline & Bilateral & 0 & 1 & \\
\hline Major nodule diameter (mm) & & $8(5-33)$ & $25(20-60)$ & $<0.003$ \\
\hline \multirow[t]{5}{*}{ Echoic pattern } & Hypoechoic & 5 & 5 & \multirow[t]{5}{*}{0.4} \\
\hline & Hyperechoic & 2 & 0 & \\
\hline & Isoechoic & 3 & 0 & \\
\hline & Anechoic & 0 & 0 & \\
\hline & Mixed & 4 & 4 & \\
\hline Intranodal vascularity & & 7 & 6 & 0.94 \\
\hline Intranodal calcifications & & 3 & 2 & 0.99 \\
\hline Lymph node involvement & & 0 & 5 & $<0.0001$ \\
\hline
\end{tabular}


Table 4

Cytological, histological data, malignancy rate and FNAB accuracy for each cytological category.

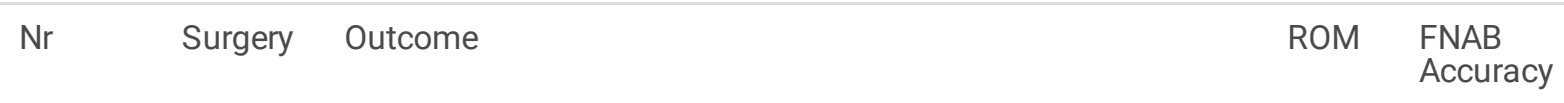

SIAPEC

category

$7 \quad$ - Ultrasound and FNAB follow-up, $\quad 0 \% \quad-$

TIR1 $\quad(9.3 \%)$

3 TIR2 at FNAB repetition

$\begin{array}{lllll}\text { TIR1C } & 4 & 1 & \text { Ultrasound follow-up; } & 0 \%\end{array}$

$1 \mathrm{ST}$ for cystic nodule and dysphagia

$\begin{array}{llllll}\text { TIR2 } & 22 & 5 & \text { Ultrasound follow-up; } & 0 \% & 100 \%\end{array}$

$(29.3 \%)$

5 TT for important MNS

$\begin{array}{llllll} & 14 & 1 \mathrm{TT} & 5 \mathrm{ST} \text { with adenoma histological diagnosis } & 0 \% & 100 \% \\ \text { TIR3a } & (18.7 \%) & 5 \mathrm{ST} & & \end{array}$

1 TT with MNS histological diagnosis

8 patients still undergoing ultrasound/FNAB follow-up

$\begin{array}{lllll}9 & 7 \mathrm{TT} & \text { All subjects underwent surgery; } & 77.8 \% & 77.8 \% \\ & (12 \%) & 2 \mathrm{ST} & \end{array}$

7 TT of which 5 PDTC histological diagnosis, 1 PMC and 1 FDTC

2 ST with NS histological diagnosis

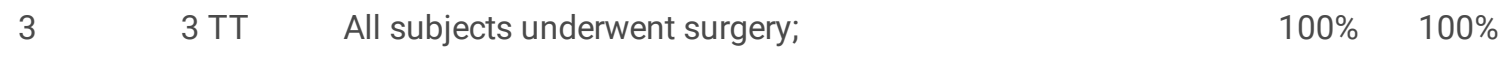

TIR4

$(4 \%)$

PDTC histological diagnosis in all subjects

\begin{tabular}{llll}
\hline 16 & 16 TT $\quad$ All subjects underwent surgery; & $100 \%$ & $100 \%$
\end{tabular}

TIR5 $(21.4 \%)$

PDTC histological diagnosis in all subjects

$75 \quad 40$

$65 \% \quad 95 \%$

Total

ROM - rate of malignancy ST - subtotal thyroidectomy TT - total thyroidectomy

MNS - multinodular struma NS - nodular struma

PDTC - papillary differentiated thyroid carcinoma 
Table 5

Comparison of the present study, the main adult studies based on the SIAPEC classification and the main pediatric studies based on the BSRTC system

\begin{tabular}{|c|c|c|c|c|c|c|c|}
\hline Reference & FNAB/ Histology & TIR1 & TIR2 & TIR3a & TIR3b & TIR4 & TIR5 \\
\hline Present study & $75 / 40$ & $0 \%$ & $0 \%$ & $0 \%$ & $77.8 \%$ & $100 \%$ & $100 \%$ \\
\hline \multicolumn{8}{|c|}{ Adult studies based on SIAPEC 2014} \\
\hline \multirow[t]{2}{*}{ Tartaglia [33] } & $-/ 52$ & - & - & $6.7 \%$ & $54.5 \%$ & - & - \\
\hline & (only indeterminate) & & & & & & \\
\hline \multirow[t]{2}{*}{ Medas [34] } & $-/ 102$ & - & - & $21.1 \%$ & $57.8 \%$ & - & - \\
\hline & (only indeterminate) & & & & & & \\
\hline \multirow[t]{2}{*}{ Ulisse [35] } & $-/ 50$ & - & - & $13.1 \%$ & $44.4 \%$ & - & - \\
\hline & (only indeterminate) & & & & & & \\
\hline \multirow[t]{2}{*}{ Straccia [36] } & $452 / 172$ & - & - & $16 \%$ & $28 \%$ & $85 \%$ & $100 \%$ \\
\hline & (only indeterminate) & & & & & & \\
\hline \multirow[t]{2}{*}{ Trimboli [37] } & $63 / 51$ & - & - & $7.5 \%$ & $54.5 \%$ & - & - \\
\hline & (only indeterminate) & & & & & & \\
\hline \multirow[t]{2}{*}{ Rullo [38] } & $-/ 290$ & - & - & $10.2 \%$ & $43.8 \%$ & - & - \\
\hline & (only indeterminate) & & & & & & \\
\hline \multirow[t]{2}{*}{ Valebrega [39] } & $157 / 75$ & & & $4 \%$ & $48 \%$ & & \\
\hline & (only indeterminate) & & & & & & \\
\hline \multirow[t]{2}{*}{ Trimboli [40] } & $-/ 74$ & - & - & $12.1 \%$ & $42.4 \%$ & - & - \\
\hline & (only indeterminate) & & & & & & \\
\hline \multirow[t]{2}{*}{ Quaglino [41] } & $-/ 150$ & - & - & $20.8 \%$ & $60.3 \%$ & - & - \\
\hline & (only indeterminate) & & & & & & \\
\hline \multirow[t]{2}{*}{ Rullo [42] } & $-/ 111$ & & & $14.5 \%$ & $54 \%$ & & \\
\hline & (only indeterminate) & & & & & & \\
\hline \multirow[t]{2}{*}{ Sparano [43] } & $562 / 273$ & - & - & $25 \%$ & $40.4 \%$ & - & - \\
\hline & (only indeterminate) & & & & & & \\
\hline \multirow[t]{2}{*}{ Cozzolino [44] } & $96 / 65$ & - & - & - & $38.5 \%$ & - & - \\
\hline & (only TIR3b) & & & & & & \\
\hline Total & & - & - & $14.2 \%$ & $44.7 \%$ & - & - \\
\hline \multicolumn{8}{|c|}{ Pediatric studies based on BSRTC } \\
\hline Monaco [46] & $179 / 96$ & $0 \%$ & $7 \%$ & $28 \%$ & $58 \%$ & $100 \%$ & $100 \%$ \\
\hline Rossi [47] & $245 / 64$ & $0 \%$ & $0 \%$ & $11.8 \%$ & $81.8 \%$ & $100 \%$ & $100 \%$ \\
\hline Lale [48] & $282 / 78$ & $17 \%$ & $0 \%$ & $50 \%$ & $47 \%$ & $100 \%$ & $100 \%$ \\
\hline Norlen [49] & $66 / 39$ & $0 \%$ & $0 \%$ & $22 \%$ & $100 \%$ & $100 \%$ & $100 \%$ \\
\hline Buryk [50] & $76 / 36$ & $0 \%$ & $10 \%$ & $0 \%$ & $50 \%$ & $86 \%$ & $100 \%$ \\
\hline
\end{tabular}




\begin{tabular}{|c|c|c|c|c|c|c|c|}
\hline Amirazodi [51] & $207 / 65$ & $0 \%$ & $16 \%$ & $67 \%$ & - & $71 \%$ & $100 \%$ \\
\hline Pantola [52] & $218 / 44$ & $0 \%$ & $0 \%$ & $8.3 \%$ & $10 \%$ & $100 \%$ & $100 \%$ \\
\hline Partyka [53] & $186 / 61$ & $0 \%$ & $1.5 \%$ & $21 \%$ & $57.1 \%$ & $100 \%$ & $100 \%$ \\
\hline Cherella [54] & $430 / 190$ & $11 \%$ & $0.7 \%$ & $44 \%$ & $71 \%$ & $73 \%$ & $97 \%$ \\
\hline Heider [55] & $46 / 41$ & - & - & $36 \%$ & $20 \%$ & $100 \%$ & - \\
\hline Kardelen [56] & $80 / 37$ & $0 \%$ & $25 \%$ & $100 \%$ & $75 \%$ & $85.7 \%$ & 100 \\
\hline Wang [57] & $302 / 104$ & $0 \%$ & $7 \%$ & $20 \%$ & $25 \%$ & $100 \%$ & $100 \%$ \\
\hline Suh [58] & $141 / 111$ & $22 \%$ & $3.2 \%$ & $75 \%$ & $50 \%$ & $100 \%$ & $100 \%$ \\
\hline Vuong [59] & $827 / 300$ & $30 \%$ & $50 \%$ & $66.6 \%$ & $36.4 \%$ & $100 \%$ & $99.3 \%$ \\
\hline Total & & - & - & $39.5 \%$ & $41.5 \%$ & - & - \\
\hline
\end{tabular}

